\title{
o "Manual dos Prefeitos e Vereadores"
}

O Deputado Federal Nelson Omegna, tepresentante de São Paulo no Congresso Nacional, ex-ministro do Trabalho, professor e autoridade consagrada em assuntos de govêrno e administração municipal, é o autor do Projeto de Lei n. ${ }^{\circ} 4.294 / 58$ que a Revista do Serviço Público publica, nesta oportunidade. Nos têtmos do referido Projeto de Lei deverá o Conselho Nacional de Pesquisas promover a organização e divulgação do "Manual dos Prefeitos e Vereadores", por intermédio do I.B.B.D. (Instituto Brasileiro de Bibliografia e Documentação), com a participação do D.A.S.P. e da Associação Brasileira de Municipios (A.B.M.). A simples leitura do texto e a Justificação do Projeto n. ${ }^{\circ} 4.294 / 58$ demonstra o elevado sentido técnico-cultural e o caráter de essencialidade do magno empreendimento que nêle se consubstancia. Trata-se de uma iniciativa de natureza rigorosamente prática e de grandes proporções, no âmbito da indispensável assistência técnica que o Govêrno Federal empreende em beneficio das Unidades elementares da Federação, os 2.500 Municipios brasileiros. A repercussão do Projeto do Deputado paulista, em tôdas as Prefeituras e Câmaras Municipais do Pais, foi excepcional. O "Manual dos Prefeitos e Vereadores" está sendo aguardado, com justificada ansiedade, como uma das mais autênticas e nobres conquistas do Movimento Mu nicipalistas Brasileiro, do qual, aliás, o ex-Ministro NELSON OMEgNa é um dos mais destacados Lideres. (N. R.).

\section{PROJETO N. ${ }^{\circ} 4.294-1958$}

Autoriza o Conselho Nacional de Pesquisas a organizar e publicar, por intermédio do Instituto Brasileiro de Bibliografia e Documen. tação, o "Manuel dos Prefeitos e Vereadores"; estabelece as hases da participação do D.A.S.P. e da Associação Brasileira de Municípios na realização conjunta dêsse empreendimento e dá outras providências.

(As Comissões de Constituição e Justiça, de Economia e de Finanças)

O Congresso Nacional decreta:

Art. 1. $\mathrm{O}$ Conselho Nacional de Pesquisas fica expressamente autorizado a promover a organização - por interméd o do Instituto Brasileiro de Bibliografia e Documentação - do "Manual dos Prefeitos e Vereadores". 
Art. 2. ${ }^{\circ}$ A fim de realizar o empreendimento a que se refere o artigo anterior, deverá o Conselho Nacional de Pesquisas entrar em entendimentos imediatos com •) Departamento Administrativo do Serviço Público (D.A.S.P.) e a Associação Brasileira de Municipios (A.B.M.) tendo em vista a elaboração de um Convênio Especial em que se estabeleçam as bases da participação das mencionadas entidades no planejamento, organização e publicação do "Manual dos Prefe:tos e Vereadores".

§ 1. O Conselho Nacional de Pesquisas far-se-á representar, nos têrmos do Convênio Especial ora previsto, pelo Instituto Brasileiro de Bibliografia e Documentação, órgão espec:alizado de pesquisas e informações cientificas e técnicas, sob sua jurisdição.

§2. O Departamento Administrativo do Serviço Público proporcionará tôdas as facilidades e a colaboração que se fizer necessária através dos Cur'sos de Administração e do Serviço de Documentação, - órgãos integrantes de sua estrutura em condições de cooperar nos trabalhos de organ:zação do "Manual dos Prefeitos e Vereadores".

§ 3. A Associação Brasileira de Municipios encaminhará ao Instituto Brasileiro de B bliografia e Documentação as contribuições técnicas, teses, estudos, projetos. indicações, anais e demais documentos oriundos dos Congressos Nacionais de Municipios e das Conferências Regionais de Prefeitos e Vereadores, inclusive dos conclaves realizados pelas Associações Estaduais.

§ 4. A Assoc'ação Brasileira de Municip:os participará da elaboração do "Manual dos Prefeitos e Vereadores" em tôdas as suas fases, em regime de urgência e intima articulação com o Instituto Brasileiro de Bibliografia e Documentação.

Art. 3. O "Manual dos Prefeitos e Vereadores" tem as seguntes finalidades primordiais: a) capacitar o Poder Executivo a proporcionar às Prefeituras e Câmaras Municipais orientação técnica e completa assistência no tocante ao equacionamento dos problemas fundamentais dos Municipios e à formação das soluções técnicas e práticas que os mesmos requerem; $b$ ) efetuar - levantamento integral das investigações, pesquisas, estudos, leis, projetos, livros, ensaios, artigos, subsídios e contribuições de qualquer espécie, bibliografias especializadas, legislação básica, - em resumo, os documentos e informações indispensáveis à orientação técn ca das autoridades municipais no exercício de suas atribuições especificas de govêrno e admin:stração; c) servir como texto básico, subsidiàriamente, nos Cursos de Administração Municipal existentes ou que venham a ser criados.

Art. 4. ${ }^{\circ}$ O Grupo de Trabalho incumbido de executar os dispositivos da presente Le:, integrado pelos representantes do Instituto Brasileiro de $\mathrm{Bi}$ bliografia e Documentação, do Departamento Administrativo do Serviço Público e da Associação Bras leira de Municipios, deverá planejar, elaborar e divulgar o "Manual dos Prefeitos e Vereadores" dentro de 12 (doze) meses contadus a partir da data da publicação desta lei.

Art. 5. Fica o Poder Executivo autorizado a abrir pelo Conselho $\mathrm{Na}$ cional de Pesquisas o crédito especial de Cr\$3.000.000,00 (três milhões de cruzeiros) destinado ao Instituto Brasileiro de Bibliografia e Documentação, 
para ocorrer às despesas com o preparo, organização e publicação do "Manual dos Prefeitos e Vereadores".

Art. 6. O crédito especial aberto nos têrmos do art. $5 .^{\circ}$ será automàticamente registrado pelo Tribunal de Contas e distribuido ao Tesouro Nacional à disposição da entidade beneficiára, a qual deverá prestar contas da importância recebida na forma da lei.

Parágrafo único. Na hipótese em que o mencionado crédito especial não seja aberto, o seu quantitativo global será incluído com a mesma destinação no primeiro Orçamento Federal que se elaborar.

Art. 7. $\mathrm{O}$ Convên o Especial referido no art. $2 .^{\circ}$ regulamentará os dispositivos da presente lei e discriminará tôdas as demais medidas que se fizerem necessárias à sua plena execução.

Art. 8. Esta lei entrará em vigor na data de sua publicação.

Art. 9. Revogam-se as disposições em contrário. - Nelson Omegna.

$$
\text { Justificação }
$$

Senhor Presidente:

$\mathrm{Na}$ oportunidade em que o Movimento Mun cipalista brasileiro intersifica as suas atividades em face da próxima realização do $\mathrm{V}$ Congresso $\mathrm{Na}$ cional de Municipios - de 11 a 19 de janeiro vindouro, - na cidade do Recife, Estado de Pernambuco, torna-se imperativo acelerar as providências destinadas à elaboração do Manual dos Prefeitos e Vereadores. Trata-se de um empreendimento cuja execução está sendo ansiosamente esperada pelas Prefeituras e Câmaras Municipais de todo o Brasil de vez que foi objeto de uma Recomendação Especial do IV Congresso Nacional de Municípios encerrado a 5 de maio de 1957 na Capital Federal.

2. O Manual dos Prefeitos e Vereadores será um "Roteiro" especializado nos domínios da Administração Municipal para fins de pesquisa, orientação e consulta. A organização e divulgação do referido Manual são trabalhos de envergadura, representando, na verdade, uma contribuição técnica, original e da maior utilidade no âmbito da teor:a e da prática da moderna administração municipal. A Recomendação Especial a respe to do Manual dos Prefeitos e Vereadores resultou de uma proposta do então secretário-geral da Associação Brasileira de Municipios, Dr. Araú jo Cavalcanti, aprovada por unanimidade durante a reunião conjunta dos Conselhos Deliberativo, Diretor e Fiscal da ent dade, a 21 de janeiro de 1957. Incorporado ao Plano de Trabalho da A.B.M., o Manual dos Prefeitos e Vereadores passou a constituir uma das preocupações fundamentais das Prefeituras e Câmaras, principalmente depois que o IV Congresso Nacional de Municipios aprovou a recomendação especial que lhe diz respeito.

3. Dentre os aspectos essenciais do referido Manual (roteiro bibliográfico para o estudo da administração municipal; elementos de pesquisas e fortes de informações especializadas sôbre os problemas municipais; legislação básica), destacam-se:

a) o levantamento bibliográfico completo de todos os estudos, ensaios, artigos, livros ou contribuições técnicas sôbre os problemas de govêrno e administraçãu municipal; 
b) a enumeração, resumo e crítica das leis, decretos, códigos ou projeto: básicos de interêsse para o govêrno e administração das comunas brasileiras; os assuntos ou problemas fundamentais para as Prefeituras e Câmaras Municipais; em resumo, a legislação orgânica e básica indispensável aos Prefeitos e Vereadores no exercício quotidiano dos respectivos mandatos;

c) o sumário e estudo comparado das grandes obras ou trabalhos relativos à administração municipal no Brasil e no estrangeiro, tendo em vista, especificamente, os seguintes campos ou áreas especializadas: - organização; administração especifica; administração geral - pessoal, material, documentação, relações públicas; economia e finanças munic:pais em geral; planejamento econômico e social, urbanismo; o sistema geral da Operação Município. com suas Projeções Regionais e Locais; planos diretores e assuntos correiatos; - em sintese, tudo o que possa interessar, direta ou indiretamente, ao exato equacionamento e à solução objetiva dos múltiplos problemas que os Prefeitos e Vereadores têm de resolver na gestão das Comunas e em benefício das respectivas populações.

4. Todavia, a fim de ser levada a efeito uma obra dessas proporções, em função de princípios de rigoroso tratamento técnico e com finalidades essencialmente práticas, impõe-se o estabelecimento de um Acôrdo ou Convênio Especial entre a A.B.M. e o Instituto Brasileiro de Bibliografia e Documentação (I.B.B.D.) - órgão técnico sob a jurisdição do Conselho Nacional de Pesquisas.

5. A realização conjunta, pelas duas Entidades, de uma obra dessa envergadura constituirá, certamente, o notável serviço prestado a quase 2.500 Comunas e. conseqüentemente, ao País. Além disso o vasto material informativo de quie a A.B.M. dispõe, - inclusive os Anais e o acêrvo dos quatro Congressos Nacionais de Municípios já realizados, - é uma garantia da execução de um trabalho completo e único, talvez no gênero. Por outro lado a contribuição do Instituto Brasileiro de Bibliografia e Documentação quanto à classificação, catalogação e apresentação dêsse matérial, reunido pacientemente em vários anos de ininterruptas atividades pela Secretaria-Geral da A.B.M. constituirá, também, garantia subsidiária de perfeição técnica. Trabalhando de comum acôrdo na realização dessa obra de proporções sem paralelo no âmbito da bibliografia especializada, as duas Instituições estarão, do mesmo passo, dando cumprimento às respectivas atribuições estatutárias e servindo, de maneira prática, aos legítimos interêsses das Prefeituras e Câmaras Municipais.

As circunstâncias são inteiramente favoráveis ao início de entendimentos concretos entre a A. B. M. e o Instituto Brasileiro de Bibliografia e Documentação, preparo do Convênio, designação dos técnicos que deverão realizar os trabalhos dentro de um prazo razoável, e demais providências que forem necessárias.

Com os elementos disponiveis, uma Comissão Mista - integrada pelos representantes da A.B.M. e pelos Técnicos do I.B.B.D., - poderá levar a efeito, em pouco tempo, o serviço especial de máxima utilidade prática que é, inegàvelmente, a organização do Manual dos Prefeitos e Vereadores consoante os dispositivos do Projeto de Lei anexo. E êste é, precisamente, o 
sentido primordial de um "Roteiro" devidamente atualizado e ampliado. De fato, cumpre organizar e sistematizar quanto antes os elementos de pesquisas, as fontes de informações especializadas e a legislação básica que os adra nistradores das nossas Comunas, na qualidade de Prefeitos e Vereadores, consideram indispensáveis ao exercício permanente de suas funções executivas ou legislativas.

6. A utilidade de uma documentação dessa ordem pode ser atestada pelo êxito do trabalho pioneiro organizado pelo Dr. Araújo Cavalcantr, exSecretário-Geral da A.B.M., e enviado ao II Congresso dos Municípios realizado em São Vicente, em 1952; cêrca de 5.000 exemplares do "Roteiro" então preparado com a colaboração do Prof. Francisco Burkinski e do D.A.S.P., se esgotaram em tempo recorde. Tão grande foi a solicitação de exemplares encaminhada ao D.A.S.P. - pedidos oriundos de todos os recantos do País que, em março de 1954, o Secretário-Geral providenciou uma segunda edição, por sua vez imediatamente esgotada. Prefaciando a publicação dêsse "Roteiro Bibliográfico", o Ministro Arísio DE VIANA, então Diretor Geral do D.A.S.P. e Administrador do Plano Salte, acentuou: "O levantamento das fontes de informação especializada é tarefa aparentemente simples. Mas exige, na verdade, muita paciência, discernimento e, sobretudo, trabalho coordenado dos pesquisadores incumbidos de efetuá-lo. Prefeitos, Vereadrres, municinglistas ou simples estudiosos estão empenhados em elevar o nível de seus conhecimentos no esforrço de obtenção de informações concretas sôbre problemas a que dedicam, por assim dizer, suas energias, seu tempo, suas vidas".

Em face da utilidade prática do Manual dos Prefeitos e Vereadores já agora acrescido das teses, contribuições, ensaios, projetos e estudos diversos encaminhados ao V Congresso Nacional de Municipios, urge promover a organização do Grupo de Trabalho ou Comissão Mista responsável pela sua pronta execução nos têrmos de um Convênio Especial entre a A.B.M. e o I.B.B.D. Tal providência virá consolidar uma legitima concepção brasileira de administração de que a Operação Municipio, com suas Projeções Regionais ou Locais, é apenas o prelúdio, a auspiciosa revelação. O Sistema Geral das iniciativas, atividades e projetos integrantes da Operação Municipio demonstra que está se delineando, aos poucos, um "estilo" brasileiro de administração, uma teoria e prática de gestão planificada visceralmente adaptadas às realidades e características das Comunas brasileiras.

7. O significado primordial do empreendimento consubstanciado ao Projeto de Lei anexo é, portanto, facilitar as consultas e pesquisas dos interessados, mediante a enumeração do que é possivel encontrar nas bibliotecas dos Ministérios, dos órgãos governamenta:s e das instituições privadas inclusive nus Anaiz do Congresso Nacional - Câmara dos Deputados e Senado Federal. Desde já deve ser salientada a colaboração prestada pelos órgãos, instituiçõcs e personalidades que esmiuçarão os acervos das nossas bibliotecas, reunindo informações do maior valor para estudiosos, técnicos e administradores. E' certo, porém, que nenhum esquema traçado para os estudos de administração municipal está isento de omissões, até certo ponto inevitáveis. Convém insistir nesia advertência básica. Não é possivel concatenar trabalhos definitivos, exaustivos ou completos sôbre assuntos tão diversos. São, portanto, naturais 
as omissões freqüentemente apontadas em bibliografias, roteiros e pesquisas relativas aos temas de grande complexidade, principalmente no âmbito das ciências sociais. Surgem, diàriamente, em todos os países, contribuições novas que, aumentando o patrimônio das culturas nacionais, tornam, ao mesmo tempo, obsoletos ou superados os registros bibliográficos. As investigações culturais não param nunca. Os resultados das pesquisas efetuadas se entrelaçam num vclume crescente. Cada vez se torna mais difícil acompanhar o ritmo das publicações que, a todo o instante, vão avolumando as estantes das bibliotecas.

Isto, porém, não invalida o mérito de um Manual Básico, um Roteiro em que se reunam informações variadas e de tanta utilidade. $O$ traço predominante das indicações, elementos e fontes de informações submetidos à apreciação dos interessados diretos - prefeitos e vereadores - é o seu ecletismo: nem todos os livros, projetos, leis, ensaios ou artigos enumerados podem ser especifica e exclusivamente relativos à administração municipal. Avultam necessàriamente as contribuições de ordem histórica, politica, econômica, geográfica e sociológica. Êsse ecletismo é uma decorrênc a da mentalidade objetiva e lógica que deve predominar nos estudos do govêrno e administração municipal. Como já foi acentuado pelo Ministro Arísıo DE VIANA, “o Municipio é a própria nacionalidade reduz da à sua expressão ma:s simples. A administracão municipal terá, por conseguinte, de encerrar, no seu bôjo, problemas da Terra e do Homem - suas angústias, suas necessidades, seu próprio destiro. Pretender examinar a administração municipal do ponto de vista exclusivamente legal pela apreciação dos aspectos juridicos em que se conf:guram os interêsses peculiares das municipalidades é pôr de lado, sem nenhuma vantagem prática, os demais aspectos, ângulos ou faces de uma realidade polivalente e dinâmica. Dai o imperativo de uma investigação ampla e compreensiva em que se considerem, simultâneamente, dados históricos, geográficos, econômicos. po'íticos, sociais administrativos". Dai o mérito excepcional do Manual dos Prefeitos e Vereadores, seu incontestável destino de utilidade... Não se pode conceber o estudo da administração municipal e seus problemas sem o conhecimento das l:gações e entrosamentos inevitáveis com as denominadas realidades brasile ras, na plenitude de suas exigências e caracteristicas. Se, por um lado, semelhante orientação alarga, evidentemente, o âmbito das matérias compreendidas ou agrupadas da denominação ampla de Administração Municipal, por outro lado, apresenta sérias vantagens decorrentes de maior objet:vidade, lucidez e racionalidade no tratamento dos problemas. As noções, fatos, questões, tendências específicas da administração municipal adquirem substância concreta, densidade de objetivos, finalidades mais práticas, melhor adequação às situações locais".

' $E$ ' indispensável a integração do espirito do estud:oso, do administrador on do politico, às condições ecológicas e b o-sociais do meio ambiente; sem o que, doutrinas e técnicas de administração municipal correm o perigo de serem transformadas em abstrações inúteis, formulações teóricas vazias de conteúdo humano e social".

\&. Algumas contribuições estrangeiras têm de, necessàriamente, fazer parte de qualquer Manual ou Roteiro para o estudo da adm nistracãn mu1 cipal e temas correlatos. Tal é o caso, entre tantos outros, dos trabalhos efe- 
tuados pela International City Managers'Association, através de seu Institute for Treíning in Municipal Administration - cursos e textos do maior alcance prático, fontes de consuita obrigatória para quantos se dediquem - cultural ou profissionalmente - ao estudo de tais assuntos.

Na elaboração do Manual, assuntos existem que, à primeira vista, estão apenas remotamente ligados aos municipios. Todavia, prefeitos e vereadores conhecem-lhes de perto a importância e as repercussões quando tratam de solucionar os problemas quotidianos das comunidades. Examinem-se, por exemplo, os temários elaborados para os Congressos Nacionais de Municipios, e ver-se-á a importância das conexões e interrelações entre determinados setores de atividades, esferas de competência ou áreas específicas em que a União, os Estados e as Comunas têm atuação e atribuições paralelas ou concorrentes. Assim, no âmbito do Direito: - assuntos juridicos, questões de legislaçãc, ensino do Direito e da Administração Municipal, leis orgânicas, reformas legais e codificações; os aspectos politicos, jurídicos e administrativos da Operação Município. suas Projeções Regionais e Locais; os problemas especificos da colaboração intergovernamental e interadministrativa; os consórcios intermunicipais; - no setor da Economia e das Finanças; - organização agrária, organização racional da produção, escoamento da produção, armazéns reguladores e entrepostos agrícolas, bancos municipais, cooperativas, energia elétrica, imigração e colonização, migrações internas, êxodo rural; o desenvolvimento planificado dos Municípios, tal como preconizado pela Operação Município - orçamento; tributação; contabilidade; prestação de contas e assim sucessivamente; no campo da Assistência Social: - ensino primário, ensino profissional rural, assistência médica, dentária e farmacêutica, habitações populares; na esfera do Planejamento Municipal: - doutrinas e técnica do planejamento global - politico, administrativo, econômico, financeiro e social; urbanismo; obras, empreendimentos e serviços; avaliação de custos; convênios e acôrdos intergovernamentais e interadministrativos - isto é, a Operação Mitnicípio em seus aspectos técnicos, econômicos, financeiros.

Percebe-se com facilidade como é vital para os Municipios e seus habitantes a exata apreciação dêsses problemas. O estudo criterioso de tantas questões essenciais deve ser orientado de maneira que os administradores preíeitos, vereadores e técnicos, - tenham uma noção mais clara de suas respcnsabilidades a par de um conhecimento mais perfeito de normas e métodos racionais de trabalho.

9. Com a realização dos sucessivos Congressos Nacionais de Municípios, recrudesce, em todo o Brasil, o interêsse pelo estudo dos problemas de administração municipal. Por outro lado a atuação dos organismos e instituiçōes municipalistas, tais como a A.B.M., o I.B.A.M., a Confederação Nacional de Prefeitos e Vereadores, as entidades regionais de que a Associação dos Municipios de Pernambuco é uma alta expressão e modêlo singular - contribuem para incentivar o interêsse pelo Municipalismo o qual, no momento, é uma idéia-fôrça da nacionalidade. Todos êsses Congressos - o primeiro dos quais levado a efeito em abril de 1950 , em Petrópolis - constituem uma excelente oportunidade para apresentação de teses, ensaios, monografias, projetos e contribuições técnicas dignas de ponderado exame. Uma das grandes 
vantagens do Manual é a divulgação de tais trabalhos que revelam, por sua vez. vocações e inteligências voltadas para o estudo dos problemas fundamentais dos Municípios. Trabalhos que devem ser reunidos, enumerados e analisados, tal como propõe o Manual, para posterior referência, consulta ou utilização.

10. Outro aspecto da maior importância para as Prefeituras, Câmaras Municipais e autoridades em geral, é que o Manual dos Prefeitos e Vereadores tem cono um dos seus objetivos enumerar, resumir e analisar os Projetos de Lei em andamento do Congresso Nacional, assim como as Leis básicas sancinnadas pelo Poder Executivo que dizem respeito aos problemas, necessidades ou reivindicações fundamentais dos Municipios brasileiros. Para que se tenha uma idéia aproximada da utilidade de tais informações, basta enumerar, a título de exemplo, algumas recentes proposições legislativas ora apreciadas pelas Comissões Técnicas da Câmara dos Deputados, ou do Senado Federal:

1) Projeto n. ${ }^{\circ} 3.112-57$ - Institui Bases e Diretrizes para a Organização do Plano Nacional de Obras, Empreendimentos e Serviços Municıpais;

2) Projeto n. ${ }^{\circ} 3.386-57$ - Autoriza o Poder Executivo a abrir, pelo Ministério da Viação e Obras Públicas, o crédito especial de Cr\$15.000.000,00 (qquinze milhões de cruzeiros) para, em colaboração com o Govêrno do Estado de Pernambuco, participar do esquema de financiamento misto da "Operação Timbaúba" (Desenvolvimento Econômico e Social do Município de Timbaúba, Estado de Pernambuco);

3) Projeto n. ${ }^{\circ}$ 3.581-57 - Autoriza o Poder Executivo a abrir, pelo M.V.O.P _ o crédito especial de Cr $\$$ 15:000.000,00 (quinze milhões de cruzeiros) como contribuição do Govêrno Federal à realização da "Operação Rio Bonito" (Desenvolvimento Planificado do Municipio: I - Obras, Empreendimentos e Serviços de Desenvolvimento Econômico e Social; II - Plano Diretor da Cidade; III - Reorganização Administrativa; IV - Atos Complementares).

4) Projeto n. ${ }^{0}$ 3.508-57 - Dispõe sôbre a participação da Associação dos Municípios de Pernambuco (A.M.P.) no Orçamento-Geral da Ünião; estabelece um Convênio Especial de Colaboração e Assistência Técnica e dá outras providências;

5) Projeto n. ${ }^{\circ}$ 3.622-57 - Dispốe sôbre a Contribuição do Govêrno Federal à execução da "Operação Cabo Frio" (Desenvolvimento Planificado do IVinicipio: I - Obras, Empreendimentos e Serviços de Desenvolvimento Econĉmico e Social; II - Plano Diretor da Cidade; III — Reorganização Administrativa; IV - Atos Complementares);

6) Projeto n. ${ }^{\circ} 3.692-58$ - Dispõe sôbre a participação da Federação de Prefeitos, Vereadores e Municipalistas Fluminenses no Orçamento-Geral da União; estabelece um Convênio Especial de Colaboração e Assistência técnica e dá outras providências;

7) Projeto n. 3.693-58 - Autoriza o Poder Executivo a abrir, pelo Ministério da Viação e Obras Públicas, o crédito especial de Cr\$15.000.000.00 (quinze milhões de cruzeiros) como contribuição do Govêrno Federal à 
raelizaçã̃o da "Operação Nilópolis" (Desenvolvimento Planificado do Município: I - Obras, Empreendimentos e Serviços de Desenvolvimento Econômico e Social; II - Plano Diretor da Cidade; III - Reorganização Administra. tiva: IV - Atos Complementares);

8) Projeto n. ${ }^{0} 3.702-58$ - Dispõe sôbre a Instituição do Plano de Recuperação e Desenvolvimento dos Municípios Brasileiros - Operação Município - e dá outras providências;

9) Projeto n..$^{\circ}$ 3.708-58 - Autoriza o Poder Executivo a abrir, pelo Ministério da Educação e Cultura, o crédito especial de Cr\$2.000.000,00 (dois milhões de cruzeiros), para ocorrer às despesas de realização do XI Congresso de Jornalistas do Interior;

10) Prfojeto n. 3.709-58 - Dispõe sôbre a participação da Associação Brasileira de Municipios (A.B.M.) no Orçamento-Geral da União; estabelece um Convênio Especial de Colaboração e Assistência Técnica e dá outras providências;

11) Projeto n. ${ }^{\circ}$ 3.736-58 - Dispõe sôbre a Contribuição do Govêrno Federal à realização da "Operação Barra do Pirai" (Desenvolvimento Planificado do Municipio: I - Obras, Empreendimentos e Serviços de Desenvolvimento Econômico e Social; II - Atos Complementares);

12) Projeto n. $3.743-58$ - Dispõe sôbre as Obras, Empreendimentos e Serviços da "Operação Arquipélago" - Reorganização Administrativa e Desenvolvimento Planificado de Fernando de Noronha; autoriza o Poder Executivo a abrir crédito especial e dá outras providências;

13) Projeto $n .^{\circ} 3.777-58$ - Dispõe sôbre o preparo e realização da I Conferência de Diretores e Chefes do Setor de Finanças das Prefeituras;

14) Projeto n. $.^{\circ} 3.869-58$ - Dispôe sôbre o preparo e realização da I Conferência de Diretores e Chefes do Setor de Agricultura das Prefeituras;

15) Projeto $n .^{\circ} 3.895-58$ - Dispõe sôbre a criação, no Departamento də Interior e Justiça do Ministério da Justiça e Negócios Interiores, da Divisão de Assistência aos Municípios, e dá outras providências;

16) Projeto $n$. $^{\circ} 3.898-58$ - Autoriza o Poder Executivo a abrir, pelo Ministério da Educação e Cultura, o crédito especial de $\mathrm{Cr} \$ 12.000 .000,00$ (doze milhões de cruzeiros), para ocorrer às despesas de realização do V Congresso Nacional de Municipios, a ser realizado em Recife, Estado de Pernambuco, em janeiro de 1959;

17) Projeto $\mathrm{n}^{\circ} 4.111-58$ - Determina a inclusão anual no Orçamento da União, de auxílio destinado ao Instituto Brasileiro de Administração Municipal (I.B.A.M.);

18) Projeto n. ${ }^{\circ} 4.122-58$ - Autoriza o Poder Executivo a abrir crédito especial, pelo Ministério da Educação e Cultura, para ocorrer às despesas de organização e realização do I Congresso da Imprensa do Interior Nordestino, em Pesqueira;

19) Projeto n. ${ }^{\circ} 4 \cdot 176-58$ - Determina a inclusão no OrçamentoGeral da União, de dotações destinadas à Confederação Nacional de Prefei- 
tos, Vereadores e Municipalistas; estabelece um Convênio Especial de Colaboração e Assistência Técnica e dá outras providências;

20) Projeto $n .^{\circ} 4 \cdot 195-58$ - Dispõe sôbre o prosseguimento da ligação ferroviária Garanhuns-Brejão-Bom Conselho, Estado de Pernambuco;

21) Projeto n. ${ }^{\circ}$ 4.227 -58 - Dispõe sôbre a Instituição e Organização do "Concurso Teixeira de Freitas"; estabelece as Bases da participação do I.B.G.E., do D.A.S.P., do Ministério da Educação e Cultura e da Associação Brasileira de Municipios na realização conjunta do referido Concurso; autoriza a abertura de crédito e dá outras providências;

22) Projeto de Resolução n. 103 da Câmara dos Deputados - Cria a Comissão dos Municipios, órgão técnico de estudos, pesquisas e colaboraçãc do Poder Legislativo com as Comunas brasileiras, Modernização e Aperfeiçoamento do Poder Legislativo, Colaboração com as Câmaras Municipais;

23) Projeto n. ${ }^{\circ}$ 4.614-54 - Dispõe sôbre as Bases e Diretrizes para a Organização do Plano Nacional de Obras, Empreendimentos e Serviços M:1nicipais (Operação Município);

24) Projeto n. ${ }^{\circ}$ 1.495-56 - Dispõe sôbre a aquisição de máquinas e equipamentos para as Prefeituras Municipais. (Projeto Complementar da Operaçàn Municipio: - regula a aplicação do art. $8 .^{\circ}$, inciso III, da Lei n. ${ }^{\circ} 2.145$, de 29-12-1953 - as importações de máquinas, motores, aparelhos, conjuntos mecanizados, implementos diversos);

25) Decreto n. ${ }^{\circ} 43.824-58$ - Dá nova redação ao art. $4 .^{\circ}$ do Decreto n. ${ }^{\circ} 41.097-57$, alterado em seu art. $7 .^{\circ}$, pelo Decreto n. ${ }^{\circ} 41.492-57$ sôbre a importação de máquinas rodoviárıas;

26) Projeto n. ${ }^{4}$ 4.257 58 - "Operação Guaxupé".

11. Os documentos acima enumerados constituem, apenas, uma pequena amostra da complexidade e importância do Manual dos Prefeitos e Vereadores no tocante à análise e divulgação dos problemas, interêsses e reivindicações básicas dos Municipios. Todo o Movimento Municipalista brasileiro está consubstanciado, por assim dizer, nos mencionados Projetos. Conforme acentuou o deputado federal PonTES VIEIRA ao submeter a alta deliberação do Congresso Nacional a Resolução n. ${ }^{\circ}$ 103-56: - "Se porventura fôsse efetuado um rigoroso levantamento das iniciativas e projetos do Con'fresso Nacional no tocante às sugestões ou tentativas de recuperação e desenvolvimento dos Municipios, ficaria a Nação surpreendida com o grande esfôrço já efetuado e o volume impressionante dos trabalhos levados a efeito quer pelos Partidos quer individualmente pelos representantes do Povo. Seria um balanço de atividades e iniciativas bastante sugestivo. Uma legítima demonstração da operosidade, espirito de colaboração e boa vontade dos nossos parlamentares. Mas, por outro lado, ter-se-á, com o referido balanço, a revelação de um panorama de dispersão, descoordenação e desperdício de preciosas energias; duplicidade de trabalhos e paralelismo de tôda ordem em detrimento das soluções tão ansiosamente procuradas. Inúmeras Mensagens do Poder Executivo e proposições legislativas referentes aos assuntos municipais -- ora em estudo nas Comissões Técnicas ou na fase de andamento 
final - justificam o pronto estabelecimento da Comissão dos Municipios, são os vários projetos de conhecimento geral sôbre serviços de abastecimento d'água; rêdes de esgotos sanitários; produção e distribuição de energia; construção de pequenas Unidades hidrelétricas; construção e conservação de rudovias intermunicipais; aquisição e utilização de máquinas e implementos agropecuários; educação e saúde; defesa de recursos naturais; conservação do solo; reflorestamento; transporte; colonização; financiamentos municipais; urbanismo; regulamentação das cotas do impôsto de renda; celebração de centenários municipais; planejamentos, reorganização administrativa, cooperativismo; regulamentação de dispositivos constitucionais e assim por diante. As populações do interior já se movimentam impacientes e começam a fazer pressãn sôbre o Congresso no sentido de um andamento mais rápido dos projetos de seu peculiar interêsse.

12. O texto do Projeto de Lei que tenho a honra de apresentar ao exame dos nobres Representantes do Povo brasileiro elucida, com objetividade e clareza, o que significa o Manual dos Prefeitos e Vereadores - emprendimento de inegável sentido cultural, finalidades técnicas e extrema utilidade prática. Tenhó a certeza de que o Congresso Nacional não poupará esforços no sentido de sua pronta aprovação, prestando destarte, mais um inestimável serviço às Prefeituras e Câmaras Municipais de todo o Brasil. Nelson Omegna, Deputado Federal. 